\title{
Metagovernance and Policy Forum Outputs in Swiss Environmental Politics
}

Manuel Fischer (manuel.fischer@eawag.ch) $)^{1,2}$. Corresponding author.

Isabelle Schläpfer (isabelle.schlaepfer@izfg.unibe.ch) ${ }^{3}$

${ }^{1}$ Department of Environmental Social Sciences, Swiss Federal Institute of Water Science and Technology (Eawag), Überlandstrasse 133, 8600 Dübendorf, Switzerland

${ }^{2}$ Institute of Political Science, University of Berne, Fabrikstrasse 8, 3012 Bern, Switzerland.

${ }^{3}$ Interdisciplinary Center for Gender Research, University of Berne, Vereinsweg 23, 3012 Bern, Switzerland.

This document is the accepted manuscript version of the following article: Fischer, M., \& Schläpfer, I. (2017). Metagovernance and policy forum outputs in Swiss environmental politics. Environmental Politics, 26(5), 870-892. https : //doi .org/10.1080/09644016.2017.1284981 


\begin{abstract}
Policy forums are lightly institutionalized and stable forms of governance networks which include administrative authorities, interest groups, and scientists. They are said to produce different types of outputs, from simple actor coordination to position papers and implementation documents, but their productivity has also been questioned. Metagovernance strategies can improve the capability of policy forums to produce outputs. This paper studies how different metagovernance strategies influence the capability of forums to produce joint position papers. It compares 29 policy forums in the Swiss environmental sector through a Qualitative Comparative Analysis (QCA). Results indicate that metagovernance strategies such as state actors as forum members or majority decision rules need to be combined with small forum size or low actor heterogeneity. Furthermore, forum foundation by the state complicates the production of position papers.
\end{abstract}




\section{Keywords}

Policy forum; collaborative governance; metagovernance; network management; environmental position papers; Switzerland 


\section{INTRODUCTION}

Policy forums are lightly institutionalized and stable forms of governance networks within the landscape of collaborative and participatory governance (Ansell and Gash 2008, Newig and Fritsch 2009, Fischer 2012). They include administrative authorities, interest groups, and scientists, and deal with a given issue area (Fischer and Leifeld 2015). ${ }^{1}$ Policy forums address policy issues in domains such as health, economic regulation, technology, or the environment. Environmental policy often involves scientific complexities and cross-boundary phenomena, and policy forums are thus important to address potential coordination deficits between different types of actors at different levels of decision-making, and from different societal sectors. Policy forums do not directly decide on laws and regulations, but they can produce important outputs ranging from the simple creation of actor coordination and mutual knowledge to the production of policy recommendations or joint position papers (Ostrom 1990, Mayntz and Scharpf 1995, Bryson et al. 2006, Börzel and Risse 2010).

However, policy forums and similar organizations have also been criticized for being simple talk-shops without producing any tangible outputs (Lubell 2004, Sörensen and Torfing 2005, Bauer and Steurer 2014). Forums are designed in a horizontal, informal and inclusive way, and are thus the opposite of traditionally hierarchical forms of policy-making led by the state administration (Hahn et al. 2006, Bates et al. 2013). This absence of clear structures of accountability or leadership complicates the production of tangible outputs. Metagovernance strategies and network management allow to address this challenge. Both refer to different tools which allow actors to steer governance networks and facilitate interactions, and thus to improve the capability of forums to produce outputs (e.g., Klijn et al. 1995, Jessop 2002, Sörensen and Torfing 2009, Van Der Heijden 2015). Most often, metagovernance is exercised by state actors or public managers, but also private actors might play such a role (Klijn et al. 1995, Sörensen and Torfing 2009). Managing policy forums is however no simple task. Different types of metagovernance strategies exist and can be combined in different ways. In this study, we 
address the following research question: How do different strategies of metagovernance affect the capability of policy forums to produce position papers?

Position papers are one specific output of policy forums. They are highly policy-relevant, as they reflect the aggregated opinion of a broad range of actors, and thus provide a potentially crucial input to formal policy-making processes (Mayntz and Scharpf 1995, Freeman 2006, Freeman and Maybin 2011, Kowalski and Jenkins 2015). The analysis takes into account five types of metagovernance strategies. First and second, state actors can influence the functioning of policy forums by either founding a forum, or by being a forum member. Third, majority rules of decision-making facilitate the production of position papers, as no consensus is needed among actors. Fourth and fifth, the number and heterogeneity of forum members influences the nature of interactions within forums. All five factors are expected to positively or negatively affect the transaction costs of interactions within policy forums.

The remainder of this paper proceeds as follows. In a first theoretical part, we define policy forums and discuss their potential outputs. We then elaborate on metagovernance strategies and the five conditions expected to influence the capability of forums to produce position papers. Empirically, we compare 29 policy forums in the Swiss environmental sector. We rely on a Qualitative Comparative Analysis (QCA), and on data gathered from documentary sources and a survey among forum managers. After presenting our cases, data and method, we present and discuss results of the comparative analysis. Finally, we formulate some conclusions from our study.

\section{THEORY}

\section{Policy forums in a governance system}

Policy forums are part of the institutional complexity of a governance system (Ostrom 2005, Lubell et al. 2010). They are lightly institutionalized and stable forms of interaction between administrative authorities, interest groups, and scientists. Policy forums deal with a narrow or 
broad issue area (Bates et al. 2013, Fischer and Leifeld 2015). Their purpose is to address issues which traditional institutions within the governance system have a hard time addressing, given a lack of integration and coordination between different types of actors and societal sectors (Bryson et al. 2006, Ansell and Gash 2008, Emerson et al. 2012). More generally, the importance of policy forums in modern governance systems can be attributed to several parallel phenomena: a coordination deficit provoked by the general decline of hierarchical decisionmaking and the development of inclusive, participatory forms of decision-making, the complexity of policy problems which involve different policy sectors and the need for coordination among them, the increased need for scientific knowledge with respect to given policy problems, and the need to design stable and long-term policy solutions for long-term problems such as, for example, climate change.

Although policy forums do also exist in other policy domains, such as health, technology, or in the form of corporatist arrangements in economic governance, they are especially prominent in the environmental sector (Lubell et al. 2002, Crona and Parker 2012). Environmental issues are not only highly complex from a scientific point of view. They also concern different administrative levels and cross administrative boundaries, and imply collective action problems and common good tragedies (Ostrom 1990). Successful environmental policy-making therefore requires the broad inclusion of different types of stakeholders, scientific expertise, and representatives from public administration at different levels. Policy forums are one way to address potential coordination deficits and facilitate coordination among these different actors (Fischer and Leifeld 2015). As such, they fulfil an increasingly important role in modern governance systems.

\section{Outputs of policy forums}

Policy forums do not produce one specific output. They rather create a platform for actor coordination and the creation of mutual knowledge. Given that such intangible outputs are 
difficult to assess, and their consequences for actual policy-making hard to evaluate, it has been suggested that policy forums are mostly talk-shops without producing actual outputs (Lubell 2004, Sörensen and Torfing 2005, Bauer and Steurer 2014). However, more tangible outputs can follow from the initial creation of coordination. Policy forums can foster joint problem understandings, joint definitions of policy problems, and, as a consequence, produce joint position papers or policy recommendations (Ostrom 1990, Mayntz and Scharpf 1995, Sörensen and Torfing 2009, Börzel and Risse 2010, Fischer and Leifeld 2015). Different types of outputs can be evaluated by the immediate service they provide to society and the common good (Provan and Milward 2001). Bryson et al. (2006) distinguish between first-, second- and thirdorder outputs: first-order outputs are immediate consequences of forum participation, such as the creation of networks and mutual knowledge. Second-order outputs are the consequences of first-order outputs, such as learning or the establishment of joint policy positions. Third-order outputs refer to long-term consequences, such as collaboration in the future (Bryson et al. 2006).

This analysis focuses on second-order outputs, that is, on joint position papers produced by policy forums. As compared to first-order outputs which are more difficult to assess and less directly connected to actual policy-making, position papers contain crucial information based on the integration of the knowledge and preferences of the different actors within policy forums. Position papers include the joint definition of a policy problem and the presentation of joint positions to tackle a problem related to a given issue. In addition to actors' agreement on the importance of different issues, position papers thus also require an agreement on positions and preferences on how to deal with an issue.

Even though policy forums do not directly create laws or regulations, forum outputs such as joint position papers can still directly influence formal policy-making processes (Mayntz and Scharpf 1995, Kowalski and Jenkins 2015). The literature on "governing by documents" (e.g., Freeman and Maybin 2011) emphasizes the importance of written documents for policy-making 
in general. As compared to simple discussions between actors, documents travel over time and space and therefore create a reference point or a boundary object for further discussions, as well as for formal policy-making (Freeman and Maybin 2011). Given this potential influence of position papers on real-world policy outputs, understanding what influences the capability of policy forums to produce such position papers is important.

\section{Metagovernance of policy forums}

The literature on metagovernance and network management claims that some actors can steer interactions within policy forums or similar organizations in order to increase its capability to produce given outputs (Kickert et al. 1997, Klijn 2005). Particular actors can influence forum work by initiating or financing a forum and setting rules for interaction, or acting as forum leaders or managers (Klijn and Koppenjan 2000, Leach and Pelkey 2001, Sörensen and Torfing 2009, Bauer and Steurer 2014). This steering role is often, although not exclusively, conferred to state actors and public managers, given their resource endowment and legitimacy (Klijn et al. 1995, Sörensen and Torfing 2009).

Following the literature on metagovernance and network management (Klijn et al. 1995, Klijn and Koppenjan 2000, Sörensen and Torfing 2009, Klijn et al. 2010), we focus on five aspects. First, the way a forum emerges (top-down, bottom-up, from outside, see Folke et al. 2005: 461) can have important effects on its functioning. If a forum is founded in a top-down manner by the state, state actors do often not only bear the financial responsibility and thus provide resources to the forum, but can also influence which actors participate in the forum, as well as define internal rules of interaction and expected outputs (Klijn and Koppenjan 2000, Jessop 2002). These tools of metagovernance are also referred to as a type of network design (Sörensen and Torfing 2009). If a forum is founded in a top-down way by state actors, they can exert metagovernance. Top-down forum foundation is thus expected to contribute to the capability of forums to produce position papers. 
Second, state actors can be simple members of policy forums. Membership allows them to facilitate and broker interactions between other forum members (Ingold and Varone 2012). State actors can also absorb transaction costs of interactions by providing critical resources such as information on the issue, or administrative capacity (Feldman and Khademian 2007, Emerson et al. 2012). What is more, state actors can cast a "shadow of hierarchy" (Scharpf 1997, Héritier and Lehmkuhl 2008) on forum interactions. Actors with low willingness to collaborate might be threatened by the "shadow of hierarchy", that is, potential sanctions from state actors which are members of the forum. Furthermore, the presence of state actors can increase the legitimacy of forum interactions and related outputs. Given these options, state membership in forums should contribute to their capability to produce position papers (Sörensen and Torfing 2009).

A third metagovernace strategy is not specific to state actors, but represents a general element of hierarchical decision-making, which should facilitate the production of forum outputs. It describes the type of decision-making within a forum, which can be consensus-oriented or majoritarian (Leach and Pelkey 2001). Policy forums are often consensus-oriented, which can prevent outside power-relations to play out in the forum, and has been shown to increase the procedural fairness as perceived by actors (Lubell 2003, Berardo 2013). However, especially if conflict between forum members is high due to different problem perceptions or policy preferences, the need to yield a consensus complicates the actual production of position papers (Choi and Robertson 2014). The use of a majority voting rule within a policy forum reduces transaction costs of negotiation, as not all forum members need to agree on a given output. Majority rules in policy forums are expected to increase their capability to produce position papers.

The last two metagovernance aspects also relate to network design (Sörensen and Torfing 2009), as they deal with the composition of policy forums. Policy forums most importantly differ with respect to the number and diversity of members (Crona and Parker 2012, Fischer 
and Leifeld 2015). Thus, as a fourth metagovernance aspect, the size of the policy forum is expected to influence the function it can adopt: whereas a broad group can develop networks and share information effectively, narrow groups can take positions on issues and act in ways broader groups cannot (Koontz and Johnson 2004). This is because the capability of selfgovernance quickly deteriorates with group size and anonymity (Olson 1965). Furthermore, actors' capacity to monitor each other decreases with increasing group size (Booher and Innes 2002). Actors additionally have only a limited capacity of digesting new knowledge and information, so that learning about the logics and interests of many other forum members is complicated. In general, transaction costs of within-group coordination increase with the number of members in a policy forum. Therefore, we expect that the more members a forum has, the lower its capability to produce position papers (Meerkerk et al. 2015).

Fifth, policy forums can include a diversity of members. They are either individuals, or-more likely_representatives of collective actors such as state agencies (at different levels), interest groups, political parties, private firms, local stakeholders or scientific organizations (Hardy and Koontz 2009). Different types of members have different functioning logics, different definitions of and perspectives on problems, as well as different preferences with respect to how a problem should be dealt with. For example, state actors have the legitimate power over decision-making and tend to strive for feasible solutions to political problems. Interest groups defend specific private or public interests, and scientific organizations tend to emphasize complexity over simple solutions readily applicable in politics (Crona and Parker 2012). Given these different logics, a heterogeneous set of forum members increases transaction costs of interactions within a forum. A forum with high heterogeneity of members should thus complicate the production of position papers (Meerkerk et al. 2015).

To sum up, we expect five aspects of metagovernance to account for the capability of policy forums to produce position papers. ${ }^{2}$ Given that we assume these factors to interact in patterns of causal complexity, we refrain from formulating explicit hypotheses (Fischer and Maggetti 
2016). Still, we expect top-down forum foundation, state membership, and a majority rule of decision-making to facilitate the production of position papers. Small size and low heterogeneity should also increase the capability of policy forums to produce outputs, whereas large size and heterogeneity of policy forums should complicate the production of such outputs.

\section{DATA AND METHODS}

\section{Selection of policy forums}

This study focuses on policy forums at the national level in Switzerland. This excludes forums dealing with a specific local problem (such as, for example, the coordination of resource users in a local watershed). Policy forums exist in many countries, but they might be especially prominent in the consensus-oriented, pluralistic and decentralized political system of Switzerland, with its traditionally dense network of interactions between the public and private spheres (Lijphart 1999, Sciarini et al. 2015).

We compare forums dealing with an environmental issue, or with an environment-related issue such as infrastructure, traffic or energy (Rieder and Mauch 2007). The identification of policy forums is based on two steps. The first exploratory step is based on a web research, starting on the website of the Swiss Federal Office for Environment. From the set of forums identified on this website, we systematically explored the websites of these forums in order to identify additional forums through weblinks. This first search step resulted in a set of 29 forums. In a postal survey, we then asked managers of these forums to indicate other policy forums in the Swiss environmental sector they were aware of (responses from 25 forums, i.e. $86 \%$ ). In this snowballing exercise, forum managers indicated 54 additional forums, from which 25 were surveyed in a second wave (responses from 14 forums, i.e. $64 \%$ ). ${ }^{3}$ The second wave of surveys also included a snowballing question, but almost no additional policy forums were mentioned. From the 39 forums, we dropped 10 forums after a second inspection, because they did not correspond to our forum definition (one was a one-shot conference, one was mainly a funding 
program, one was mainly an emergency communication body, 3 included only scientific actors, one included only interest groups), or of missing information on the number and type of members ( 3 forums) (see Table A1). The final set of 29 policy forums covers a broad range of environment-related policy sectors. Examples are "Water Agenda 21", "Energy Switzerland", "Knowledge Transfer Forest Switzerland", "Forum Biodiversity”, "National Forum for Natural Disasters" or "Information Service for Public Transport" (the full list of forums is presented in Table A1).

\section{Qualitative Comparative Analysis}

We rely on a Qualitative Comparative Analysis (QCA, e.g. Ragin 1987, Rihoux and Ragin 2009, for applications in public policy, see Schlager and Heikkila 2009, Fischer 2015) to compare the policy forums. QCA allows for the systematic comparison of a medium number of cases and is based on set-theory and Boolean algebra. Cases are described by fuzzy-set values for both the causal conditions and the outcome to be explained. Fuzzy-set values lie between 0 and 1 and indicate the degree to which a case is a member in a given set, for example the set of policy forums that produce position papers (Ragin 2008, Rihoux and Ragin 2009). Whereas a value of 1 indicates full membership of a case in the set of policy forums producing position papers, a fuzzy-set value of 0 represents full non-membership in the set of policy forums producing position papers.

A truth table is the basis of the comparative analysis and presents all observed configurations of conditions. For each configuration of conditions (corresponding to a row in the truth table), the researcher then assesses its empirical relation to the outcome. The assessment of this relation is based on the fuzzy-set values of all cases, summarized by a consistency score. ${ }^{4}$ Configurations that are consistently related to the outcome are included in the analysis. The algorithm then reduces the configuration of conditions that are related to the outcome by eliminating redundant conditions and finally identifies necessary and sufficient conditions 
related to an outcome. QCA is most often used as a tool to explore data and develop new hypotheses (Rihoux and Ragin 2009, Fischer and Maggetti 2016). Given the medium number of cases and the complex results including many interactions among conditions, proper hypothesis testing is difficult. This analysis thus serves to test existing arguments and inspire new hypotheses with respect to the functioning of policy forums.

\section{Calibration of outcome and conditions}

The outcome of this analysis is given by one specific type of policy forum output, that is, joint position papers. In our survey, managers of policy forums were asked whether or not the production of position papers was an output of their forum. 22 of the 29 forums included in our analysis $(76 \%)$ produce position papers. The outcome is coded as a crisp-set (corresponding to a simple dichotomous variable), with forums producing joint position papers coded as 1 , and the other forums coded as $0 .^{5}$

The five metagovernance conditions are operationalized as follows. First, the information on whether a forum was founded in a top-down way by state actors, or in a bottom-up manner by other actors, stems from our survey. We asked forum managers to indicate whether their forum was founded by state actors, scientific actors, or societal actors directly affected by the problem. The condition is coded as a crisp-set, with forums founded by state actors coded as 1 , and forums founded by other actors as 0.7 out of 29 forums under study were founded in a topdown manner by the state. Second, the information on the membership of a state actor in a forum stems from official documents, that is, official lists of forum members available on the forum websites. We again rely on a crisp-set coding: If at least one national-level state actor is a member of the forum, this creates the possibility of meta-governance exercised by the state. Such forums are thus coded as 1 , forums with no national-level state actors as members are coded as 0. State actors are members in 21 out of 29 forums. ${ }^{6}$ 
Third, we base the information on whether a forum takes majority decisions or not (meaning that it allows for multiple voices or takes consensus decisions) on a respective survey item. It again operates on a crisp-set logic, with forums taking majority decisions coded as 1 , and others as 0.11 out of 29 forums take majority decisions. Fourth, forum size is assessed by the number of members of a policy forum. This number ranges from a maximum of 64 actors ("Forum Biomasse") to a minimum of 5 actors ("Kompost Forum" and "Forum Früherkennung Biodiversität und Landschaft"). As no straightforward theoretical scale for a maximum forum size is readily available, we transform this simple actor count into continuous fuzzy-sets by calculating the relative size of forums as compared to the observed minimum (5, corresponding to a fuzzy-value of 0$)$ and maximum (64, corresponding to a fuzzy-value of 1$)$ values.

The fifth condition assesses the heterogeneity of the set of forum members by calculating the percentage of interest groups represented in the forum (as opposed to state actors, scientific actors, or private firms). ${ }^{7}$ Again, given the absence of meaningful theoretical thresholds, the empirically observed maximum value across the 29 cases (71\%, “Agridea") serves as an upper threshold (fuzzy-value of 1), and the observed minimum value serves as a lower threshold (fuzzy-value of 0 , nine different forums). We calculate continuous fuzzy-set values as the relative heterogeneity compared to the observed maximum. The distribution of the latter two variables in their non-calibrated form appear in Appendix $3 .^{8}$ The raw data matrix displaying the values for all 29 cases across the outcome and the five conditions appears in the appendix (Table A2).

\section{Analysis and discussion}

The combination of five conditions results in 32 possible configurations, from which 14 are empirically observed in the dataset and appear in Table 1. TDOWN stands for forums founded in a top-down manner by the state, MEMBER represents the set of forums wherein a state actor is a member, and MAJ stands for forums deciding with a majority rule. HETERO represents 
the set of forums with a heterogeneous set of members, SIZE the forums of large size. The consistency scores indicate to what extent the empirical observations support the postulate that the combination of conditions in a row of the truth table is sufficient for the emergence of the outcome. Rows with a consistency value of at least 0.85 are coded with the value 1 for the presence of the outcome, the others are coded as 0 , for the absence of the outcome (Schneider and Wagemann 2010). ${ }^{9}$ For the reduction of the solution term, we focus on the complex solution. It is the most conservative solution, as it makes no assumptions with respect to nonobserved combinations of conditions. ${ }^{10}$

\section{--- Table 1 about here ---}

The solution appears in Table 2. It consists of four parts (one per row), which describe four alternative combinations of conditions that relate to forums which produce position papers. The consistency and coverage scores express to what extent statements about set-theoretic relations between conditions and the outcome enjoy empirical support. ${ }^{11}$ An overall consistency value of 0.93 indicates that the solution formula is to a very large degree consistent with empirical evidence. An overall coverage value of 0.75 means that $75 \%$ of the outcome values are covered by the solution formula. The last column indicates the cases covered by each partial solution term (for case numbers, see Table A1).

\section{--- Table 2 about here ---}

The graphical representation of the solution in Figure 1 presents the result in a more intuitive way. The lower four rows represent the four combinations of conditions related to the outcome. White dots represent the absence of a given condition, black dots indicate its presence, and empty cases mean that the respective condition is not part of this specific combination of 
conditions, that is, its presence or absence does not matter for understanding the outcome. For example, the first row represents the first partial solution in Table 2. It means that policy forums which are not founded in a top-down manner by the state, function with a majority rule, and contain a rather homogeneous set of actors are able to produce position papers.

\section{--- Figure 1 about here ---}

With respect to the effects of single conditions, empirical results mostly correspond to theoretical expectations. State membership or majority decision rules enable policy forums to produce position papers (with one exception for the majority rule in solution 3). Also, as expected, small forum size or low heterogeneity contribute to the capability of policy forums to produce position papers. One condition, however, does not have the expected influence. We expected that top-down forum foundation by state actors would indicate a potential leading role by the state, which would then facilitate the production of position papers. Yet, on the contrary, the absence of top-down forum foundation, that is, the forums founded in a bottom-up way by either societal or scientific actors, is part of three combinations of conditions which enable forums to produce position papers (solutions 1-3). If a forum is founded in a top-down way, state membership and majority decision-making are additionally needed for a forum to produce position papers. Related to top-down and bottom-up founded policy forums, results thus suggest a different mechanism than expected by metagovernance theory. It appears that top-down forum foundation by the state could be less of an indicator of potential leadership, but point to a lack of commitment by societal and scientific actors. As suggested by socio-psychological arguments (Frey 2012), strong external intervention by state actors might decrease the intrinsic motivation of societal and scientific actors to actively deal with a given issue. This again complicates the interactions within a policy forum and its capability to produce position papers. 
Looking at the combination of conditions, results show an interesting pattern of combinations between different types of metagovernance strategies. First, all solutions include at least two metagovernance strategies. This confirms our general expectation that different types of metagovernance strategies interact with each other when affecting policy forum outputs. Second, the analysis suggests that policy forums are able to produce position papers if state actors are members of policy forums, or policy forums work with majority rules of decisionmaking, and that one of the two aspects of forum composition additionally facilitates forum interactions. Whereas state membership needs to be combined with either small forum size or low forum heterogeneity, a majority rule of decision-making works only in combination with low forum heterogeneity. Third, there appears to be a trade-off between the size of a forum and the heterogeneity of its members, as suggested in the literature (Krause and Douglas 2013). Forums which produce position papers are either small or consist of a homogeneous set of actors.

The first solution (see Table 2) covers 8 policy forums. An example representing the combination of a forum founded in a bottom-up way, working with majority rules of decisionmaking, and being composed of a homogeneous set of actors is "Info Flora". This forum deals with the documentation and conservation of Switzerland's wild plants. It consists of mostly administrative and scientific actors, and some interest group members which represent mostly environmental associations. Scientific and societal actors have founded the forum, and it takes majority decisions. Examples for outputs are a red list of endangered flowers (Bornand et al. 2016), a black list of invasive plants (Buholzer et al. 2014) and other information material. An example for the second combination of conditions, that is, bottom-up founded forums with state actors as members and a homogeneous set of members (the respective solution covers 12 forums), is "Biomasse Suisse". This policy forum deals with the promotion of energy production from biomass. It includes a large set of actors (64), but is rather homogenous, as it involves mainly private firms dealing with recycling and eco-technology. Furthermore, state 
administrative actors responsible for energy and environmental issues are involved, as they are strongly interested in gaining information on the potential of this energy source. An example of a position paper by this forum is its answer to the consultation procedure organized by the state administration on the new regulations on energy and power supply (Biomasse Suisse 2016). The position of this policy forum thus represents a direct input into a policy process.

The third solution term, that is, a combination of bottom-up forum foundation, state membership and no majority rule of decision-making with a small number of forum members, covers 8 forums. An example is "Water Agenda 21", which functions in three different, small (10-13 individuals) working groups and involves mainly specialists in the water domain from research institutes and different levels of government. It was founded upon the initiative of scientists and practitioners concerned by the lack of coordination and information exchange in the water sector, but the Swiss agency for the environment acts as a leading member. An example of a joint position paper produced by Water Agenda 21 is the "Leitbild Einzugsgebietmanagement" (guiding principles for integrated water basin management, Wasser-Agenda 21 2011) This document presents important aspects and examples of integrated water of river basins, and supports a respective program by the Swiss national government to foster these types of new institutional arrangements for the management of water bodies.

Fourth, there are two examples which suggest that policy forums founded in a top-down way can still produce position papers. To do so, they need to be of small size, have state actors as members, and work with a majority rule. One example is the policy forum "Runder Tisch Kunststoff Recycling” (roundtable on plastic recycling), which consist of 15 actors representing several state levels, the recycling business and retailers. Following a report by the Swiss environmental agency, the policy forum produced a position paper which explained the current state of plastic recycling efforts and policies in Switzerland, proposed different policy options for increasing the respective recycling effort, and related these potential policies to ongoing 
policy-making projects and inquiries by members of parliament (Schelker and Geisselhardt 2011).

\section{Conclusions}

This study aimed at examining the factors contributing to the capability of policy forums to produce outputs. Policy forums are one phenomenon in the broad landscape of collaborative and participatory governance (Ansell and Gash 2008, Newig and Fritsch 2009, Fischer 2012). They are not supposed to directly take decisions in the form of laws and regulations, but can produce otherwise important outputs that range from the mere organization of meetings or and the establishment of mutual knowledge among actors to the production of policy recommendations or joint position papers (Ostrom 1990, Mayntz and Scharpf 1995, Sörensen and Torfing 2009, Börzel and Risse 2010). Position papers coming out of policy forums can be important inputs for formal policy-making (Mayntz and Scharpf 1995, Freeman and Maybin 2011, Kowalski and Jenkins 2015). The analysis relies on five well-established arguments with respect to conditions which are supposed to influence the productivity of policy forums and similar organizations.

Our comparative analysis of 29 policy forums in the domain of Swiss environmental policy suggests two main interesting and innovative findings. First, different types of metagovernance strategies can help to increase a forum's capability to produce joint position papers. The factors of state actors as forum members and rules of majority decision-making need to combine with a small number or a low heterogeneity of forum members. Specific combinations of strategies of metagovernance are thus likely to reduce transaction costs of actors' interactions and thereby increase the productivity of policy forums. Second, and differently than expected, top-down forum foundation does not appear as a successful metagovernance strategy. We suspect that it rather indicates the absence of intrinsic motivation by interest groups or scientific actors to work together in a forum (Frey 2012). This then complicates the elaboration of joint position papers. 
On the contrary, bottom-up forum foundation by society or science actors is important for forums to be able to produce position papers. This is an important finding, as it suggests that a careful combination of both self-organization of political actors (that is, bottom-up forum foundation based on intrinsic motivation) and a moderate shadow of hierarchy (state membership or a majority rule) represents an effective combination of conditions which allows forums to actually produce outputs.

There are of course caveats to the present analysis, which should motivate further studies. First, not all policy forums might actually aim at producing position papers. Our analysis is not implying such a claim, but simply presents the configurations of conditions related to policy forums which actually produce joint position papers. Other forums might either not be able or not willing to produce such outputs.

Second, the comparison of 29 policy forums in Swiss environmental policy shows some interesting patterns between forum outputs and complicating and facilitating factors. Results mostly correspond to prior theoretical knowledge, or suggest meaningful new theoretical arguments. Still, in order to show that these patterns correspond to causal paths to understand why given forums are capable of producing position papers, future research needs to test these arguments in other contexts, and with other methods. For example, going back to the individual cases in more detail is important, as the broad comparative analysis in this paper does not leave space for detailed analyses of single policy forums. More in-depth analyses of single policy forums could not only describe the number and heterogeneity of forum members, but also focus on the quality and quantity of their interactions in order to understand what outputs a policy forum produces (Crona and Parker 2012, Kowalski and Jenkins 2015).

Third, our analysis deals with the specific domain of environmental policy in the context of the Swiss political system. As argued in the introduction, the work of policy forums might be especially important in the domain of environmental policy, due to scientific complexities and boundary-spanning phenomena. However, the conditions included in our analysis are not 
specific to environmental policy, but apply to any type of policy forum. We therefore see no reason to assume that our results are specific to this domain.

Furthermore, while policy forums as defined in this paper exist in many other countries, we cannot exclude that the consensus-oriented, pluralistic and decentralized political system of Switzerland (Lijphart 1999, Sciarini et al. 2015) facilitates the creation of policy forums, and interactions within them. More facilitating factors might need to be present in more confrontational political systems, or a top-down forum foundation might have less of a negative effect on forum outputs in political systems with stronger traditions of centralized, hierarchical decision-making. Fourth and finally, while this study asks under which conditions policy forums produce position papers, it does not deal with the crucial subsequent step in the policy process, that is, the question of how such position papers influence actual policy-making. Outputs from policy forums are based on the joint work of different types of actors from different levels dealing with a given issue. Therefore, the literature (Freeman 2006, Freeman and Maybin 2011), as well as our empirical examples, suggest that forum outputs such as for example joint position papers have some weight in the policy process. However, on the more critical side, one might also argue, for example, that a position paper which is passed by a majority rule might be of limited value for actual policy-making, given that not all actors in the policy forum had to agree. In this case, the diversity of actors related to the issue might not be taken into account, which could hamper innovation (Booher and Innes 2002). This idea points to only one of the many open research questions related to the issue of policy forums. 


\section{Endnotes}

${ }^{1}$ Concepts like bridging organization (Hahn et al. 2006, Crona and Parker 2012, Kowalski and Jenkins 2015), hybrid advisory committee (Krick 2015), boundary organization (Crona and Parker 2011), collaborative institution (Lubell et al. 2010) or partnership (Leach et al. 2002, Selsky and Parker 2005, Bauer and Steurer 2014) are used in the literature to describe policy forums.

${ }^{2}$ Note that while we frame these factors as metagovernance strategies in this analysis, not all of them are in the reach of actors which might want to metagovern a forum. While state actors might be able to join a policy forum in order to try to improve its functioning through brokerage or a shadow of hierarchy, forum heterogeneity is inherently more difficult to influence, as it not only depends on state actors, but also on other actors which are members of the forum.

${ }^{3}$ Others were excluded because they were not policy forums in our definition, but interest groups or implementation organizations. The second wave of surveys revealed no additional policy forums which were not already included in the first wave, indicating that we have covered a reasonable population of policy forums in Swiss environmental policy.

${ }^{4}$ The consistency score provides information on the extent to which the empirical observation supports the postulate of a perfect relationship between the conditions and the outcome, or how well the solution formula describes the cases. The coverage score is an indicator of the empirical importance of a relationship. It indicates what proportion of the fuzzy-membership values of the cases in the set of the outcome can be explained by the solution (Ragin 2008).

${ }^{5}$ We acknowledge that policy forums might be more or less productive, that is, the number of position papers produced by policy forums might strongly differ between forums. Our analysis focuses on the difference between forums which do produce (any number of) position papers, and those who do not produce position papers.

${ }^{6}$ Regional state actors (Swiss cantons) are members in some forums. Given that we concentrate on policy forums with a national focus, we do not take regional state actors into account for operationalizing state membership.

${ }^{7}$ This is admittedly only a rough proxy to account for the potential heterogeneity of interests within a policy forum. Another possibility would have been to take into account also private firms, which are strongly represented in some forums. However, by definition, interest groups represent broader interests than single, private firms. Accordingly, operationalizing heterogeneity with the ratio of both interest groups and private firms results in a solution with lower coverage and corresponds less well to theoretical expectations. 
${ }^{8}$ Alternative calibrations rely on a) $95 \%$ instead of $71 \%$ (for HETERO) and 75 (for SIZE) as upper thresholds, b) observed gaps in the data as crossover points ( 0.44 for hetero, 33 for size, see Appendix 3$)$, or c) observable gaps in the data distribution for HETERO ( 0 for values between 0 and $0.1,0.33$ for values between 0.11 and $0.3,0.66$ for values between 0.31 and $0.45,1$ for values above 0.45 , see Appendix 3). Results are identical to the one presented in the paper, with the only exception of the fourth solution path being size*hetero*MEMBER*MAJOR instead of size*TDOWN*MEMBER*MAJOR for calibrations a) and b). This indicates that results are robust to different possible types of calibrations based on the data distribution.

${ }^{9}$ This threshold is clearly above the 0.75 minimum threshold recommended by Schneider and Wagemann (2010) and corresponds to the major gap in consistency values in the truth table.

${ }^{10}$ Analyses are conducted with fsQCA (Ragin et al. 2009) and the QCA package in R (Thiem and Dusa 2013). Both reveal the same results.

${ }^{11}$ In the tables, * stands for logical "and". Conditions and outcomes written with capital letters stand for their presence; those in lower-case letters indicate absence of the phenomenon. 


\section{References}

Ansell, C., and Gash, A., 2008. Collaborative governance in theory and practice. Journal of Public Administration Research and Theory, 18 (4), 543-71.

Bates, L. E., Green, M., Leonard, R., and Walker, I., 2013. The influence of forums and multilevel governance on the climate adaptation practices of Australian organizations. Ecology and Society, 18 (4).

Bauer, A., and Steurer, R., 2014. Innovation in climate adaptation policy: are regional partnerships catalysts or talking shops? Environmental Politics, 23 (5), 818-38.

Berardo, R., 2013. The coevolution of perceptions of procedural fairness and link formation in self-organizing policy networks. The Journal of Politics, 75 (3), 686-700.

Biomasse Suisse, 2016. Stellungnahme zur Änderung der Energieverordnung (EnV) und der Stromversorgungsverordnung (StromVV). Zollikon: Biomasse Suisse.

Booher, D. E., and Innes, J. E., 2002. Network power in collaborative planning. Journal of Planning Education and Research, 21 (3), 221-36.

Börzel, T., and Risse, T., 2010. Governance without state: can it work? Regulation \& Governance, 4 (2), 113-34.

Bonard, C., Gygax, A., Juillerat, P., Juzti, M., Möhl, A., Rometsch, S., Sager, L., Santiago, H., Eggenberg, S., 2016. Rote Liste Gefässpflanzen. Gefährdete Arten der Schweiz. Bern / Genf: Bundeamt für Umwelt / Info Flora.

Bryson, J. M., Crosby, B. C., and Stone, M. M., 2006. The design and implementation of crosssector collaborations: propositions from the literature. Public Administration Review, $66(1), 45-55$.

Buholzer, S., Nobis, M., Schoenenberger, N., Rometsch, S., 2014. Liste der gebietsfremden invasiven Arten der Schweiz. Genf: Info Flora.

Choi, T., and Robertson, P. J., 2014. Deliberation and decision in collaborative governance: a simulation of approaches to mitigate power imbalance. Journal of Public Administration Research and Theory, 24 (2), 495-518.

Crona, B. I., and Parker, J. N., 2011. Network determinants of knowledge utilization: preliminary lessons from a boundary organization. Science Communication, 33 (4), 44871.

, 2012. Learning in support of governance: theories, methods, and a framework to assess how bridging organizations contribute to adaptive resource governance. Ecology and Society, 17 (1), 32-50.

Emerson, K., Nabatchi, T., and Balogh, S., 2012. An integrative framework for collaborative governance. Journal of Public Administration Research and Theory, 22 (1), 1-29.

Feldman, M. S., and Khademian, A. M., 2007. The role of the public manager in inclusion: creating communities of participation. Governance, 20 (2), 305-24.

Fischer, F., 2012. Participatory governance: from theory to practice. In: D. Levi-Faur, ed. The Oxford Handbook of Governance. Oxford: Oxford University Press, 457-72.

Fischer, M., 2015. Institutions and coalitions in policy processes: a cross-sectoral comparison. Journal of Public Policy, 35 (2), 245-68.

Fischer, M., and Leifeld, P., 2015. Policy forums: why do they exist and what are they used for? Policy Sciences, 48 (3), 363-82.

Fischer, M., and Maggetti, M., 2016. Qualitative Comparative Analysis and the study of policy processes. Journal of Comparative Policy Analysis: Research and Practice, published online.

Folke, C., Hahn, T., Olsson, P., and Norberg, J., 2005. Adaptive governance of sociotechnological systems. Annual Review of Environmental Resources, 30, 441-70.

Freeman, R., 2006. The work the document does: research, policy, and equity in health. Journal of Health Politics, Policy and Law, 31 (1), 51-70. 
Freeman, R., and Maybin, J., 2011. Documents, practices and policy. Evidence \& Policy: A Journal of Research, Debate and Practice, 7 (2), 155-70.

Frey, B. S., 2012. Crowding out and crowding in of intrinsic preferences. In: E. Brousseau, T. Dedeurwardere, and B. Siebenhüner, eds. Reflexive governance for global public goods. Massachusetts: Massachusetts Institute of Technology, 75-83.

Hahn, T., Olsson, P., Folke, C., and Johansson, K., 2006. Trust-building, knowledge generation and organizational innovations: the role of a bridging organization for adaptive comanagement of a wetland landscape around Kristianstad, Sweden. Human Ecology, 34 (4), 573-92.

Hardy, S. D., and Koontz, T. M., 2009. Rules for collaboration: institutional analysis of group membership and levels of action in watershed partnerships. Policy Studies Journal, 37 (3), 393-414.

Héritier, A., and Lehmkuhl, D., 2008. The shadow of hierarchy and new modes of governance. Journal of Public Policy, 28 (01), 1-17.

Ingold, K., and Varone, F., 2012. Treating policy brokers seriously: evidence from the climate policy. Journal of Public Administration Research and Theory, 22, 319-46.

Jessop, B., 2002. The future of the capitalist state. Cambridge: Polity Press.

Kickert, W. J. M., Klijn, E.-H., and Koppenjan, J. F. M., 1997. Introduction: a management perspective on policy networks. In: W. J. M. Kickert, E.-H. Klijn, and J. F. M. Koppenjan, eds. Managing complex networks. Strategies for the public sector. London: Sage, 1-13.

Klijn, E.-H., 2005. Designing and managing networks: possibilities and limitations for network management. European Political Science, 4 (3), 328-39.

Klijn, E.-H., and Koppenjan, J., 2000. Public management and policy networks. Foundations of a network approach to governance. Public Administration, 2 (2), 135-58.

Klijn, E.-H., Koppenjan, J., and Termeer, K., 1995. Managing networks in the public sector: a theoretical study of management strategies in policy networks. Public Administration, 73 (3), 437-54.

Klijn, E.-H., Steijn, B., and Edelenbos, J., 2010. The impact of network management on outcomes in governance networks. Public Administration, 88 (4), 1063-82.

Koontz, T. M., and Johnson, E. M., 2004. One size does not fit all: matching breadth of stakeholder participation to watershed group accomplishments. Policy Sciences, 37 (2), 185-204.

Kowalski, A. A., and Jenkins, L. D., 2015. The role of bridging organizations in environmental management: examining social networks in working groups. Ecology and Society, 20 (2).

Krause, G. A., and Douglas, J. W., 2013. Organizational structure and the optimal design of policymaking panels: evidence from consensus group commissions' revenue forecasts in the American states. American Journal of Political Science, 57 (1), 135-49.

Krick, E., 2015. Negotiated expertise in policy-making: how governments use hybrid advisory committees. Science and Public Policy, 42 (4), 487-500.

Leach, W. D., and Pelkey, N. W., 2001. Making watershed partnerships work: a review of the empirical literature. Journal of Water Resources Planning and Management, 127 (6), 378-85.

Leach, W. D., Pelkey, N. W., and Sabatier, P. A., 2002. Stakeholder partnerships as collaborative policymaking: evaluation criteria applied to watershed management in California and Washington. Journal of Policy Analysis and Management, 21 (4), 64570.

Lijphart, A., 1999. Patterns of democracy: government forms and performance in thirty-six countries. New Haven: Yale University Press. 
Lubell, M., 2003. Collaborative institutions, belief-systems, and perceived policy effectiveness. Political Research Quarterly, 56 (3), 309-23.

, 2004. Collaborative environmental institutions: all talk and no action? Journal of Policy Analysis and Management, 23 (3), 549-73.

Lubell, M., Henry, A. D., and McCoy, M., 2010. Collaborative institutions in an ecology of games. American Journal of Political Science, 54 (2), 287-300.

Lubell, M., Schneider, M., Scholz, J. T., and Mete, M., 2002. Watershed partnerships and the emergence of collective action institutions. American Journal of Political Science, 46 (1), 148-63.

Mayntz, R., and Scharpf, F., 1995. Gesellschaftliche Selbstregulierung und politische Steuerung. Frankfurt: Campus.

Meerkerk, I. V., Edelenbos, J., and Klijn, E.-H., 2015. Connective management and governance network performance: the mediating role of throughput legitimacy. Findings from survey research on complex water projects in the Netherlands. Environment and Planning C: Government and Policy, 33 (4), 746-64.

Newig, J., and Fritsch, O., 2009. Environmental governance: participatory, multi-level - and effective? Environmental Policy and Governance, 19 (3), 197-214.

Olson, M., 1965. The logic of collective action. Harvard: Harvard University Press.

Ostrom, E., 1990. Governing the commons. The evolution of institutions for collective actors. Cambridge: Cambridge University Press.

— 2005. Understanding institutional diversity. Princeton: Princeton University Press.

Provan, K. G., and Milward, H. B., 2001. Do networks really work?. Public Administration Review, 61 (4), 414-23.

Ragin, C., Drass, K. A., and Davey, S., 2009. Fuzzy-set/Qualitative Comparative Analysis 2.5. [Computer program].

Ragin, C. C., 1987. The comparative method. Moving beyond qualitative and quantitative strategies. Berkeley: University of California Press.

,2008. Redesigning social inquiry: fuzzy-sets and beyond. Chicago/London: University of Chicago Press.

Rieder, S., and Mauch, C., 2007. Entwicklung einer Zusammenarbeitsstruktur im Bereich Wasser. Luzern: Interface Politikstudien.

Rihoux, B., and Ragin, C. C., 2009. Configurational Comparative Methods: Qualitative Comparative Analysis (QCA) and related techniques. Thousand Oaks/London: SAGE Publications.

Scharpf, F. W., 1997. Games real actors play: actor-centered institutionalism in policy research. Boulder, CO: Westview Press.

Schelker, R., and Geisselhardt, P., 2011. Projekt "Kunststoff Verwertung Schweiz. Studie im Auftrag des Bundesamt für Umwelt (BAFU). Basel: Redilo GmbH.

Schlager, E., and Heikkila, T., 2009. Resolving water conflicts: a comparative analysis of interstate river compacts. The Policy Studies Journal, 37 (3), 367-92.

Schneider, C. Q., and Wagemann, C., 2010. Standards of good practice in Qualitative Comparative Analysis (QCA) and fuzzy-sets. Comparative Sociology, 9 (3), 397-418.

Sciarini, P., Fischer, M., and Traber, D., 2015. Political decision-making in Switzerland. The consensus model under pressure. Basingstoke: Palgrave Macmillan.

Selsky, J. W., and Parker, B., 2005. Cross-sector partnerships to address social issues: challenges to theory and practice. Journal of Management, 31 (6), 849-73.

Sörensen, E., and Torfing, J., 2005. The democratic anchorage of governance networks. Scandinavian Political Studies, 28 (3), 195-218.

Sörensen, E., and Torfing, J., 2009. Making governance networks effective and democratic through metagovernance. Public Administration, 87 (2), 234-58.

Thiem, A., and Dusa, A., 2013. Qualitative Comparative Analysis with R. New York: Springer. 
Van Der Heijden, J., 2015. The role of government in voluntary environmental programmes: A fuzzy set Qualitative Comparative Analysis. Public Administration, 93 (3), 576-92.

Wasser-Agenda 21, 2011. Einzugsgebietsmanagement. Leitbild für die integrale Bewirtschaftung des Wassers in der Schweiz. Bern: Wasser-Agenda 21. 


\section{Appendix 1}

\section{Table A1. List of policy forums.}

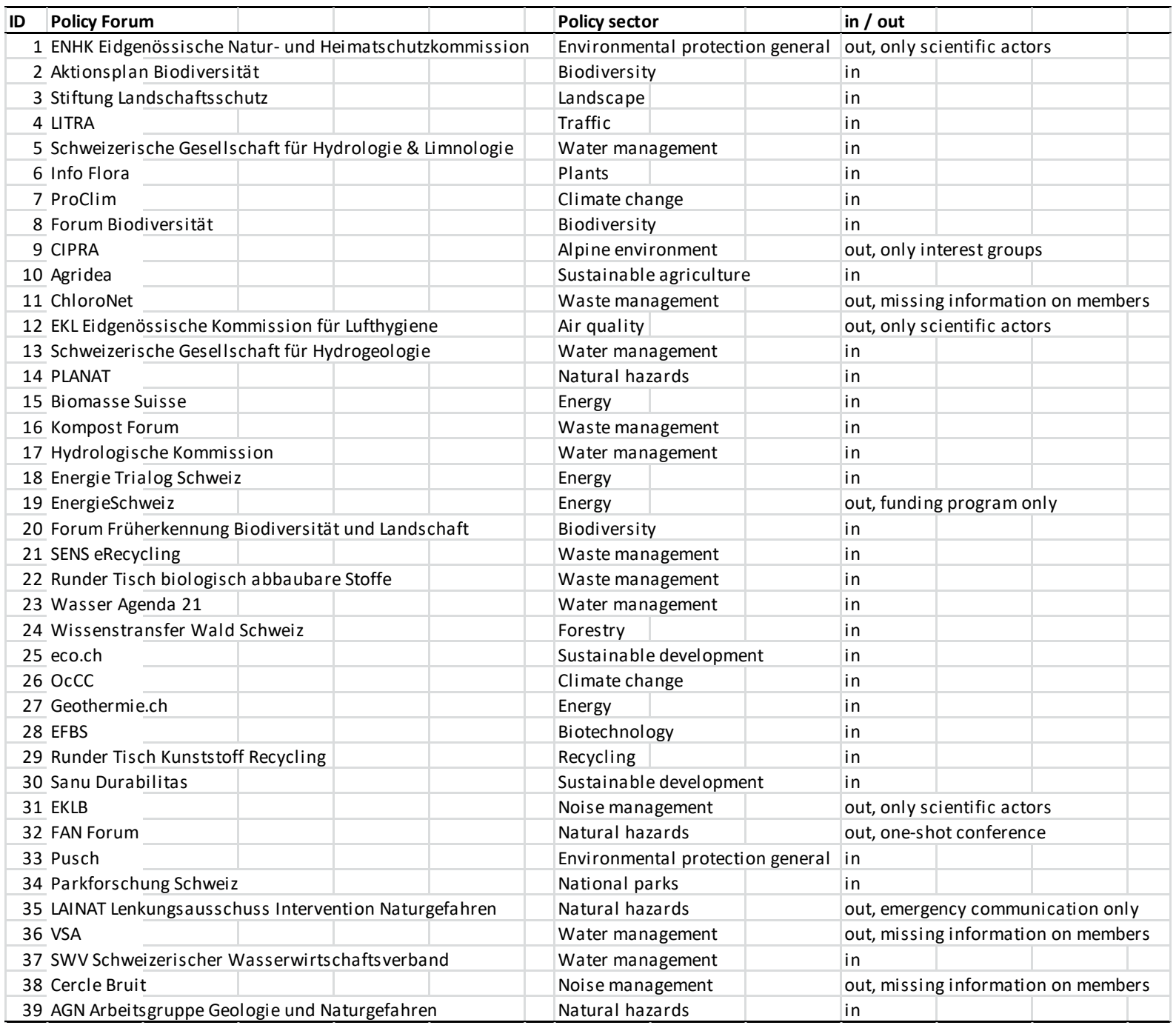




\section{Appendix 2}

Table A2. Raw data matrix

\begin{tabular}{|c|c|c|c|c|c|c|}
\hline ID & POSI & TDOWN & MEMBER & MAJOR & HETERO & SIZE \\
\hline 2 & 1 & 1 & 1 & 1 & 0,61 & 0,42 \\
\hline 3 & 1 & 0 & 0 & 0 & 0,53 & 0,19 \\
\hline 4 & 1 & 0 & 0 & 1 & 0,06 & 0,76 \\
\hline 5 & 1 & 0 & 1 & 0 & 0,07 & 0,24 \\
\hline 6 & 1 & 0 & 1 & 1 & 0,37 & 0,24 \\
\hline 7 & 1 & 0 & 1 & 0 & 0,00 & 0,14 \\
\hline 8 & 1 & 0 & 1 & 1 & 0,13 & 0,64 \\
\hline 10 & 0 & 1 & 1 & 1 & 1,00 & 0,92 \\
\hline 13 & 1 & 0 & 1 & 1 & 0,00 & 0,46 \\
\hline 14 & 1 & 1 & 1 & 0 & 0,00 & 0,27 \\
\hline 15 & 1 & 0 & 1 & 0 & 0,02 & 1,00 \\
\hline 16 & 1 & 0 & 0 & 1 & 0,28 & 0 \\
\hline 17 & 1 & 0 & 1 & 0 & 0,00 & 0,17 \\
\hline 18 & 0 & 0 & 0 & 0 & 0,48 & 0,46 \\
\hline 20 & 0 & 1 & 1 & 0 & 0,00 & 0 \\
\hline 21 & 1 & 0 & 0 & 1 & 0,06 & 0,32 \\
\hline 22 & 1 & 0 & 1 & 0 & 0,49 & 0,25 \\
\hline 23 & 1 & 0 & 1 & 0 & 0,85 & 0,08 \\
\hline 24 & 0 & 1 & 1 & 0 & 0,40 & 0,03 \\
\hline 25 & 0 & 0 & 1 & 1 & 0,75 & 0,39 \\
\hline 26 & 1 & 1 & 1 & 0 & 0,00 & 0,08 \\
\hline 27 & 1 & 0 & 1 & 1 & 0,10 & 0,15 \\
\hline 28 & 1 & 1 & 1 & 1 & 0,00 & 0,24 \\
\hline 29 & 1 & 0 & 1 & 0 & 0,56 & 0,17 \\
\hline 30 & 0 & 0 & 1 & 0 & 0,23 & 0,12 \\
\hline 33 & 1 & 0 & 0 & 1 & 0,10 & 0,15 \\
\hline 34 & 0 & 1 & 1 & 0 & 0,00 & 0,17 \\
\hline 37 & 1 & 0 & 1 & 0 & 0,24 & 0,80 \\
\hline 39 & 1 & 0 & 1 & 0 & 0,00 & 0,14 \\
\hline
\end{tabular}


Appendix 3

Figure A1: Distribution of HETERO (non-calibrated values)

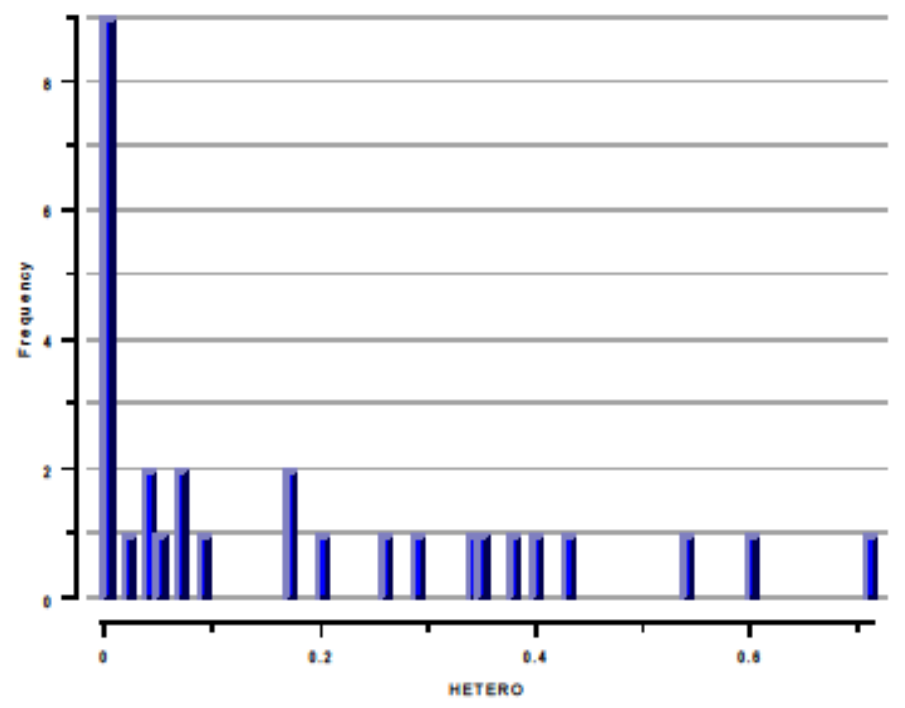

Figure A2: Distribution of SIZE (non-calibrated values)

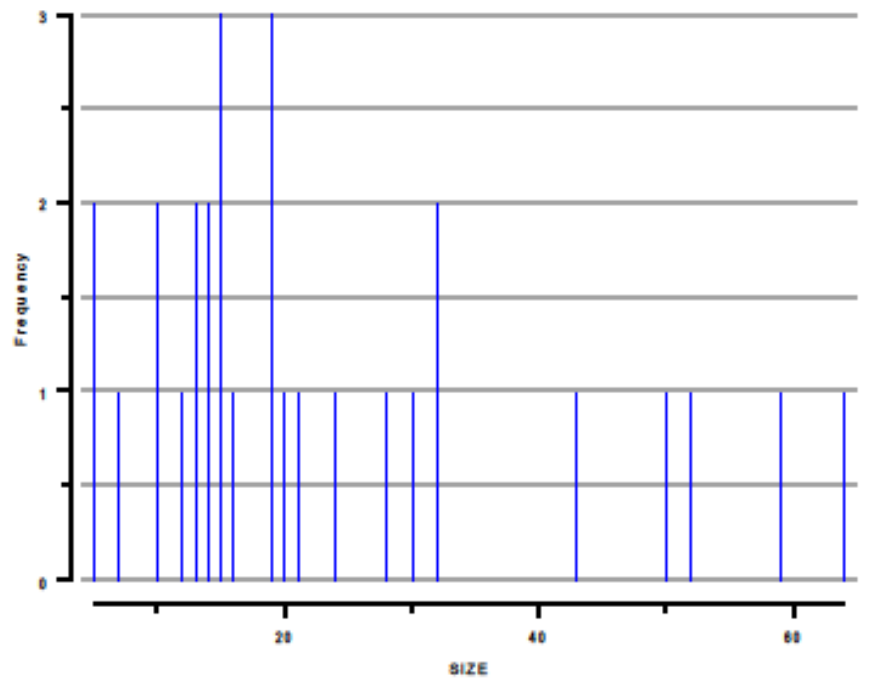


Table 1. Truth table

\begin{tabular}{cccccccc}
\hline TDOWN & MEMBER & MAJOR & HETERO & SIZE & Consistency & Outcome & N \\
\hline 0 & 0 & 1 & 0 & 1 & 1.00 & 1 & 1 \\
1 & 1 & 1 & 0 & 0 & 1.00 & 1 & 1 \\
0 & 0 & 1 & 0 & 0 & 1.00 & 1 & 3 \\
0 & 1 & 0 & 0 & 1 & 0.96 & 1 & 2 \\
0 & 1 & 1 & 0 & 0 & 0.91 & 1 & 3 \\
0 & 1 & 0 & 1 & 0 & 0.90 & 1 & 2 \\
1 & 1 & 1 & 1 & 0 & 0.88 & 1 & 1 \\
0 & 1 & 0 & 0 & 0 & 0.86 & 1 & 6 \\
0 & 1 & 1 & 0 & 1 & 0.86 & 1 & 1 \\
\hline 0 & 0 & 0 & 1 & 0 & 0.53 & 0 & 1 \\
0 & 1 & 1 & 1 & 0 & 0.50 & 0 & 1 \\
0 & 0 & 0 & 0 & 0 & 0.48 & 0 & 1 \\
1 & 1 & 0 & 0 & 0 & 0.40 & 0 & 5 \\
1 & 1 & 1 & 1 & 1 & 0.31 & 0 & 1 \\
\hline
\end{tabular}


Table 2. Complex QCA solution

\begin{tabular}{lcccc}
\hline & Consist. & Raw & Unique & Cases \\
cov. & & cov. & \\
\hline tdown* MAJOR*hetero + & 0.97 & 0.31 & 0.16 & $4,6,8,13,16,21,27,33$ \\
tdown*MEMBER*hetero + & 0.90 & 0.46 & 0.10 & $5,6,7,8,13,15,17,22,27,30,37,39$ \\
tdown*MEMBER*major*size + & 0.87 & 0.27 & 0.06 & $5,7,17,22,23,29,30,39$ \\
TDOWN*MEMBER*MAJOR*size & 0.94 & 0.06 & 0.06 & 2,28 \\
\hline Total consistency & 0.93 & & & \\
Total coverage & 0.75 & & & \\
\hline
\end{tabular}


Figure 1. Combination of conditions leading to position papers

\begin{tabular}{|c|c|c|c|c|c|}
\hline Solution & TDOWN & MEMBER & MAJOR & HETERO & SIZE \\
\hline 1 & 0 & & 0 & 0 & \\
\hline 2 & 0 & 0 & & 0 & \\
\hline 3 & 0 & 0 & 0 & & 0 \\
\hline 4 & 0 & 0 & 0 & & 0 \\
\hline
\end{tabular}

